Syntax Literate : Jurnal Ilmiah Indonesia p-ISSN: 2541-0849

e-ISSN : 2548-1398

Vol. 6, No. 2, Februari 2021

\title{
DETERMINASI RISIKO PERBANKAN DI INDONESIA
}

\section{Laras Muchdiarti, Muhammad Dika Primaduta dan Farah Margaretha Leon}

Universitas Trisakti, Jakarta, Jawa Barat, Indonesia

Email: muchdiantilars@gmail.com,dika.primaduta@gmail.com dan

farahmargaretha@trisakti.ac.id

\section{Abstract}

This research was conducted aims to identify what are the determinants of risk in banking in This research was conducted to identify what are the determinants of risk in banking in Indonesia. The sample used in this study is banking institutions listed on the Indonesia Stock Exchange, totaling 31 companies from 2009 - 2019 using the systematic generalized method of moment and obtained by the purposive sampling method. Banking risk as the dependent variable is measured using the $Z$ score. The results of this study show that there is a significant positive influence between the Capital Adequacy Ratio (CAR), Profitability, Banking Concentration, Domestic Credit to Private Sectors, and Current Account on banking risk. Inefficiency, Liquidity, Interest Rates, Inflation and Unemployment Rate have a significant negative effect. against banking risk, while Asset Quality shows results that do not affect banking risk. Bankng Leaders and Investors have to always observe to both bank specific and macroeconomic variables with the result that they could take appropriate steps in their policy and investment decisions.

Keywords: capital adequacy ratio (car); asset quality; inefficiency; profitability; liquidity; banking concentration; domestic credit to private sectors; interest rates; inflation; current account; unemployment rate; banking risk; z-score

\footnotetext{
Abstrak

Penelitian ini dilakukan bertujuan untuk mengidentifikasi apa saja yang menjadi determinan dari risiko pada perbankan di Indonesia. Sampel yang digunakan dalam penelitian ini adalah instansi perbankan yang terdaftar di Bursa Efek Indonesia yang berjumlah 31 perusahaan dari tahun 2009-2019 dengan menggunakan metode systematic generalized method of moment dan didapatkan dengan metode purposive sampling. Risiko perbankan sebagai variabel dependen diukur menggunakan $\mathrm{Z}$ score. Hasil dari penelitian ini menunjukan adanya pengaruh positif signifikan antara Capital Adequacy Ratio (CAR), Profitabilitas, Konsentrasi Perbankan, Kredit Domestik terhadap Pihak Swasta, dan Current Account terhadap risiko perbankan. inefisiensi, ilikuiditas, Tingkat Suku Bunga, inflasi dan tingkat pengangguran berpengaruh negatif signifikan terhadap risiko perbankan, sedangkan kualitas aset menunjukan hasil yang tidak berpengaruh terhadap risiko perbankan. Untuk para pimpinan perbankan dan para investor harus selalu memperhatikan kondisi mikro dan makro ekonominya agar bisa tepat dalam mengambil langkah dalam keputusan kebijakan dan keputusan investasinya.
} 
Kata Kunci: capital adequacy ratio (car); kualitas asset; inefisiensi; profitabilitas; ilikuiditas; konsentrasi perbankan; kredit domestik terhadap pihak swasta; tingkat suku bunga; inflasi; current account; tingkat pengangguran; risiko perbankan; z-score

Coresponden Author

Email: muchdiantilars@gmail.com Artikel dengan akses terbuka dibawah lisensi

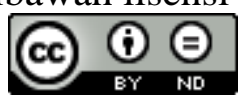

\section{Pendahuluan}

Sektor perbankan sering dianggap sebagai jantung dan motor penggerak perekonomian suatu negara (Simatupang, 2019). Berhubungan dengan transformasi modal, bank bertugas untuk menghimpun dana dan menyalurkannya lagi kepada masyarakat dan memainkan peran fundamental dalam jangka pendek maupun jangka panjang (Tran, Ha, \& Quyen, 2018). Menurut Simatupang (2019), bank adalah lembaga keuangan yang kegiatan utamanya adalah menerima simpanan dari masyarakat dalam bentuk giro, tabungan dan deposito. Selain itu bank berfungsi juga sebagai landasan perkembangan ekonomi dan daya apung sistem keuangan. Peran vital dimaikan oleh sektor keuangan terhadap pembangunan ekonomi negara dan ini terbukti dari kontribusi sektor tersebut terhadap produk domestik bruto (Edirisuriya, Gunasekarage, \& Perera, 2019).

Hancurnya sistem ekonomi tersebut yang diperankan utama oleh dunia perbankan, maka diteliti risiko-risiko terhadap kestabilan perbankan tersebut. Krisis, risiko dan regulasi perbankan adalah topik yang selalu ada dalam perdebatan kebijakan ekonomi dan krisis perbankan seringkali mempengaruhi negara berkembang dan transisi ke tingkatan yang lebih luas. Meskipun demikian ada kekurangan pemahaman faktorfaktor yang menyebabkan timbulnya risiko perbankan tersebut. Regulator dalam hal ini lebih cenderung untuk membantu dibandingkan memecahkan masalah yang menyebabkan kepailitan institusi perbankan. Sayangnya, kontrol-kontrol ini cenderung terlambat, setelah risiko nya terjadi. Oleh karena itu, pemahaman yang lebih baik tentang faktor-faktor risiko dapat membantu dalam mengurangi risiko lebih lanjut sebelum menyebar ke sistem keuangan yang lebih luas (Martínez-Malvar \& Baselga-Pascual, 2020).

Risiko perbankan adalah risiko kegiatan bank atau risiko asetnya yang dihadapi selama bank tersebut beroperasi (Li \& Malone, 2016). Z-Score adalah pengukuran utama yang dilakukan atas risiko dari masing-masing perbankan. Z- Score mencerminkan stabilitas bank yang diukur dengan probabilitas insolfensi sebuah bank (Apriadi et al., 2016). Z-Score mengukur jarak ke default suatu perbankan dan yang dimasukan ke dalam perhitungan adalah return on assets dan volatilitas laba atas aset. Semakin tinggi rasio Z-Score semakin besar jarak ke default yang berakibat semakin rendah risikonya. Sebaliknya semakin dekat jarak ke default berakibat semakin tinggi risikonya. Oleh karena itu angka yang dihasilkan dari Z-Score ini berbanding negatif 
atau berbanding terbalik dengan risiko bank (Martínez-Malvar \& Baselga-Pascual, 2020).

Z-Score kini sudah menjadi ukuran yang umum pada variabel risiko perbankan (Maudos, 2017) dan menurut Martínez-Malvar \& Baselga-Pascual (2020) analisa ZScore dari periode krisis finansial 2007 - 2009 menghasilkan keakuratan dengan tingkat signifikansi sebesar 99\%. Rumus dari Z-Score adalah:

$$
\text { Z-Score } \mathrm{i}, \mathrm{t}=\frac{R O A i, t+E T A i, t}{\sigma(R O A) i, t}
$$

Di mana ROA merupakan tingkat pengembalian rata-rata aset Bank i pada tahun t, ETA sendiri merupakan rasio ekuitas terhadap terhadap total aset Bank i pada tahun $t$. Standar deviasi atau $\sigma$ adalah deviasi dari pengembalian total aset rata-rata.

Mayoritas studi menilai bahwa pengelolaan risiko di sektor perbankan akan membentuk stabilitas keuangan yang tinggi dan lembaga yang dikelola dengan sangat baik tentunya harus memiliki sistem identifikasi yang tepat untuk dapat memantau dan mengendalikan risiko tersebut (El-Chaarani, 2019). Di Asia Tenggara sendiri para Gubernur dari Central Bank of ASEAN telah meyetujui untuk menyelaraskan kembali regulasi perbankan sebagai prasyarat pada komunitas ekonomi ASEAN, sehingga dunia perbankan akan menyesuaikan dengan regulasi tersebut dan dapat memberikan penelitian yang sangat baik untuk memeriksa hubungan regulasi bank, persaingan, dan stabilitas keuangan pada perbankan (Noman, Gee, \& Isa, 2018).

Berkaca dari latar belakang di atas dan penting nya untuk menjaga tingkat risiko suatu Bank untuk keberlangsungan ekonomi yang baik bagi suatu negara, tujuan dalam penelitian ini adalah untuk mengidentifikasi apa saja yang menjadi determinan dari risiko perbankan. Oleh karena ini peneliti tertarik untuk mengangkat judul Determinasi Risiko Perbankan di Indonesia. Maka tujuan dilakukannya penelitian ini adalah untuk mengidentifikasi apa saja yang menjadi determinan dari risiko perbankan.

Modal dapat didefinisikan sebagai variabel yang menentukan ketahanan suatu lembaga keuangan guna menahan guncangan pada neracanya (Martínez-Malvar \& Baselga-Pascual, 2020). Di Indonesia sendiri yang dinilai dalam aspek ini adalah modal yang dimiliki oleh bank yang didasarkan pada kewajiban penyediaan modal minimum yang telah ditetapkan Bank Indonesia. Ketetapan penyediaan modal ini utamanya bertujuan untuk memelihara kepercayaan nasabah terhadap Bank dan untuk menjaga atau melindungi dana pihak ketiga pada Bank itu sendiri (Purba, Darminto, \& NP Endang, 2015). Kebutuhan pengaturan permodalan bank antara lain didasarkan pada pentingnya peran kebutuhan modal sebagai disinfentif untuk pengambilan risiko oleh pemegang saham Bank, yang mungkin dikondisikan oleh keterbatasan kewajiban (Basela-Pascual et al., 2015) serta masalah moral hazard yang sering menyertai simpanan atau ekspektasi bailout oleh publik (Demirguc-Kunt, Detragiache, \& Merrouche, 2013).

Kualitas aset yaitu menilai jenis aset yang dimiliki oleh suatu perbankan (Purba et al., 2015). Kualitas aset juga mengukur kuantitas risiko kredit yang ada dan potensial 
yang terkait dengan portofolio pinjaman terhadap asetnya. Aset sendiri dapat dipengaruhi oleh penilaian pasar dan penilaian resiko reputasi, kepatuhan ataupun resiko strategis, dan dapat mempengaruhi penilaian terhadap aset tersebut. (Martínez-Malvar \& Baselga-Pascual, 2020). Kualitas aset di proxy kan dengan total loans dibagi dengan total assets. Salah satu praktik yang paling banyak dikritik dalam perbankan terkadang adalah kemudahannya memberikan pinjaman pada saat ekspansi ekonomi (Baselga-Pascual, Trujillo-Ponce, \& Cardone-Riportella, 2015).

Variabel ini mengukur kinerja individu dalam peran kepemimpinan pada perbankan. Demikian pula regulator mengharapkan perbankan untuk beroperasi dengan cara yang aman, sehat dan selalu mengindahkan budaya kepatuhan dalam sistem nya. Manajemen senior dan dewan direksi bertanggung jawab atas kesehatan dan kinerja lembaganya. (Martínez-Malvar \& Baselga-Pascual, 2020). Variabel ini diukur oleh rasio cost to income sebagai proxy (Poghosyan \& Čihak, 2011). Dalam teori Bad Management, Efisiensi biaya rendah ini dapat meningkatkan risiko dari perbankan itu sendiri, selama kualitas manajemen perbankan tersebut buruk dalam penilaian kredit ke nasabah, penaksiran jaminan dan pemantauan kredit nya (Louzis, Vouldis, \& Metaxas, 2012).

Indikator pendapatan atau profitabilitas digunakan untuk menilai kesehatan keuangan dan memantau alokasi sumber daya bank yang efisien. Seperti pada perusahaan lain pada umumnya, perbankan pun tidak dapat bertahan dalam bisnis kecuali jika perbankan tersebut menguntungkan (Martínez-Malvar \& Baselga-Pascual, 2020). Terdapat hubungan yang sangat berkaitan antara pendapatan dengan risiko. Poghosyan \& Čihak (2011) menunjukan bahwa perbankan di Eropa dengan pendapatan yang baik cenderung tidak mengalami kesulitan di tahun berjalan dan kedepannya. Untuk pengukuran dari rasio profitabilitas ini, digunakan Return On Equity (BaselgaPascual et al., 2015).

Perbankan dapat dikatakan liquid, jika Bank mampu membayar hutangnya, khususnya hutang jangka pendek, hutang jangka pendek adalah simpanan tabungan, giro dan deposito. Dikatakan liquid apabila pada saat ditagih bank sanggup untuk membayar dan Bank juga harus bisa memenuhi setiap permohonan kredit yang layak untuk dibiayai (Purba et al., 2015). Selama krisis keuangan, Bank Sentral Eropa memangkas suku bunga di bawah 0, dan membuat Perbankan di Eropa tidak memiliki simpanan pada Bank Sentral dan lebih memilih untuk investasi pada aset lainnya dibandingkan memberikan kredit ke masyarakat, sehingga dapat menaikan risiko liquiditas (Macchiarelli, 2018). Untuk proxy yang digunakan adalah Loan to Customer Deposit atau total kredit yang diberikan dibandingkan dengan penghimpunan dana pihak ketiga nya (Petria, Capraru, \& Ihnatov, 2015).

Domestic Credit to Private Sector (DCPS) memainkan peran signifikan secara ekonomi dan statistik dalam memprediksi krisis selanjutnya (Martínez-Malvar \& Baselga-Pascual, 2020). DCPS juga dapat disimpulkan untuk semua jenis krisis, dapat diidentifikasi sebagai suatu pengukuran dengan peran penting (Obstfeld, 2012). 
Ada beberapa penelitian yang mendukung pandangan bahwa Interest Rate atau tingkat suku bunga memiliki keterkaitan dengan risiko perbankan (Baselga-Pascual et al., 2015). Suku bunga dalam beberapa dekade terakhir juga mempengaruhi imbal hasil dari perbankan tersebut (Agoraki, Delis, \& Pasiouras, 2011). Selain itu, dalam konteks suku bunga yang tinggi dapat menyebabkan perbankan menurunkan kredit nya untuk mendapatkan hasil yang lebih baik (Martínez-Malvar \& Baselga-Pascual, 2020).

Inflasi (infl) dapat melipatgandakan kemungkinan krisis perbankan sistemik, untuk di Amerika Latin dapat memberikan efek yang termasuk besar bila dibandingkan dengan negara lainnya (Davis, Karim, \& Liadze, 2011). Inflasi dianggap sebagai salah satu variabel yang relevan untuk menangani indikator keuangan secara makro khusus dalam negara ekonomi berkembang (Duca \& Peltonen, 2013)

Disimpulkan bahwa ada korelasi antara Current Account (CurrAcc) dengan default baru pada sovereign debt (Reinhart \& Rogoff, 2013) dan krisis perbankan terjadi pada negara yang memiliki defisit pada Current Account nya. Begitu juga pertumbuhan kredit yang dikombinasikan dengan defisit current account dapat berkontribusi terhadap kerentanan dalam sistem perbankan (Kauko, 2012).

Tingkat pengangguran (Unpl) dapat didefinisikan sebagai adanya ketidaksesuaian antara pasokan tenaga kerja terhadap permintaan tenaga kerja, dan juga tingkat pengangguran dapat dilihat dari sisi permintaan dan penawarannya (Puspadjuita, 2017). Tingkat pengangguran ini dapat mempengaruhi pengambilan risiko pada perbankan, dikarenakan kenaikan tingkat pengangguran ini akan membuat Bank mempertimbangkan kegiatan mereka dengan cermat (Khan, Scheule, \& Wu, 2017)

Kualitas aset tentu akan mempengaruhi juga risiko dari perbankan itu sendiri. Kualitas aset yang baik dapat juga ditandai dari meningkat nya portofolio pemberian kredit nya, tetapi harus dibarengi juga dengan peningkatan total aset nya dikarenakan kenaikan ini dapat mempengaruhi risiko perbankan itu sendiri. Tidak adanya kenaikan total aset yang sesuai dengan kredit yang diberikan kepada nasabah dapat menurunkan rasio kualitas aset nya. (Martínez-Malvar \& Baselga-Pascual, 2020).

Management internal dari sebuah perbankan pada akhirnya akan tetap menentukan risiko dari sebuah perbankan itu sendiri. Apakah mereka melakukan keputusan - keputusan yang efisien dan tepat terhadap bank atau tidak. Keputusan yang efisien suatu manajemen dapat terlihat dari performa dan peranan masing-masing individual pimpinan dalam pengambilan keputusan. Regulator mengharapkan perbankan untuk tetap dapat beroperasi dengan cara yang aman dan sehat, melakukan budaya kepatuhan (Martínez-Malvar \& Baselga-Pascual, 2020).

Perbankan bisa dikatakan keluar dari jalur bisnis nya apabila dia tidak dapat menghasilkan keuntungan (Martínez-Malvar \& Baselga-Pascual, 2020). Ini menandakan bahwa profitability atau keuntungan merupakan hal yang penting dalam elemen perbankan itu sendiri. Perbankan di Eropa yang memiliki pendapatan yang bagus cenderung lebih kuat dalam menghadapi masalah keuangan di masa depan dan akan mengurangi risiko dari perbankan itu sendiri (Poghosyan \& Čihak, 2011). 
Keterkaitan antara tingkat likuiditas suatu perbankan dapat mempengaruhi risiko perbankan itu sendiri. Permasalahannya adalah perbankan memberikan kredit kepada nasabah secara jangka panjang, dan total deposits yang berhasil dihimpun adalah untuk jangka pendek, dan lama kelamaan akan menimbulkan kondisi yang disebut dengan deposits drainage. Ini memunculkan tekanan pada kondisi makro ekonomi dan menaikan risiko perbankan (Chiaramonte, Croci, \& Poli, 2015). Apabila tingkat rasio likuiditas perbankan naik sehingga menyebabkan ketidaklikuiditasan, hal ini akan menaikan juga tingkat risiko Bank tersebut (Martínez-Malvar \& Baselga-Pascual, 2020).

Hasil penelitian dari Baselga-Pascual et al., (2015) menyatakan bahwa ada hubungan negatif antara rasio kecukupan modal dan risiko. Hal ini diakibatkan karena adnya potensi bahaya dari leverage dan juga tingkat modal yang tinggi membuat Bank lebih menyaring nasabahnya secara intensif sehingga mengurangi dari risiko perbankan itu sendiri. (Laeven et al., 2016) mengatakan, Bank dengan tingkat kapitalisasi lebih besar memiliki risiko yang lebih rendah, dengan kata lain, Bank tersebut mempunyai efek yang besar dalam sistem ekonomi yang lebih besar. Berbeda dengan Penelitian Nguyen et al., (2019), menghasilkan bahwa rasio modal yang lebih besar dapat mendorong bank untuk meningkatkan risiko nya.

Berdasarkan penjelasan di atas, maka dirumuskan hipotesis sebagai berikut:

\section{H1: Terdapat pengaruh antara Capital Adequacy Ratio dengan risiko perbankan}

Kualitas aset ditunjukan dari banyaknya kredit yang diberikan ternyata bisa menurunkan tingkat risiko bank itu sendiri dan menunjukan bahwa pada bank komersial portofolio pinjaman yang lebih besar dapat menurunkan risiko. Hasil menunjukan bahwa bank berfokus pada aktivitas dasar dari maturity transformation dan cenderung memiliki risiko yang lebih kecil (Martínez-Malvar \& Baselga-Pascual, 2020). Begitu juga dengan rendah nya kualitas aset dapat menurunkan pendapatan bunga, di mana Bank tidak meningkatkan ekspansi kredit nya sehingga akan menaikan tingkat risikonya dikarenakan menurunnya aktivitas utama dari perbankan itu sendiri (Baudino, Orlandi, \& Zamil, 2018). Penelitian (Liem, Son, \& Nghia, 2016) menyatakan jika Bank menaikkan pinjaman dengan menurunkan standar pinjaman mereka seperti mengurangi persyaratan agunan dan beberapa persyaratan lain, kejadian seperti inilah yang dapat menghasilkan risiko perbankan yang lebih besar.

Berdasarkan penjelasan di atas, maka dirumuskan hipotesis sebagai berikut :

\section{$\mathrm{H}_{2}$ : Terdapat pengaruh antara kualitas aset dengan risiko perbankan}

Regulator tetap mengharapkan Bank untuk beroperasi dengan cara yang aman, sehat, dan tetap menjalankan unsur kepatuhan sehingga membutuhkan kualitas dari jajaran manajemen nya (Martínez-Malvar \& Baselga-Pascual, 2020). Bank yang lebih efisien cenderung memiliki biaya rata - rata yang lebih rendah dan biaya pendapatan yang lebih rendah (Huljak, Martin, \& Moccero, 2019) yang selanjut nya dapat mengurangi kemungkinan risiko Bank (Baselga-Pascual et al., 2015). Rendahnya biaya efisiensi atau semakin inefisiensi biaya berkorelasi positif dengan peningkatan NonPerforming Loan di masa depan karena kurangnya ketrampilan dalam penilaian 
kredit, penilaian agunan dan pemantauan peminjam sehingga menaikan risiko nya (Louzis, Vouldis, \& Metaxas, 2012).

Berdasarkan penjelasan di atas, maka dirumuskan hipotesis sebagai berikut:

\section{$\mathrm{H}_{3}$ : Terdapat pengaruh antara inefisiensi dengan risiko perbankan}

Baselga-Pascual et al., (2015) menemukan bahwa adanya hubungan negatif antara profitabilitas dengan risiko perbankan. Bahwa Bank yang lebih menguntungkan cenderung lebih stabil. Hasil penelitian dari Poghosyan \& Čihak (2011) menyatakan hal yang sama, bahwa terdapat pengaruh negatif antara profitabilitas dengan risiko perbankan, bahwa perbankan di Eropa yang memiliki tingkat profitabilitas yang tinggi memiliki kecendrungan risiko yang lebih rendah atau lebih aman. Disetujui juga oleh Köhler (2015) yang menyatakan juga bahwa kenaikan tingginya profitabilitas perbankan menandakan Bank tersebut semakin stabil dan mengurangi risiko nya.

Berdasarkan penjelasan di atas, maka dirumuskan hipotesis sebagai berikut:

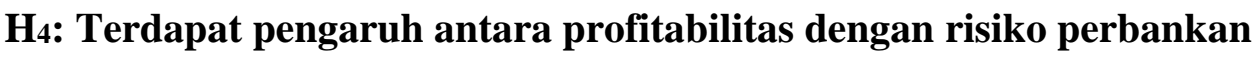

Bank dapat mengalami peningkatan tingkat risiko bila tingkat likuiditas menurun atau kenaikan ilikuiditas nya. Dapat dikatakan Bank mengalami peningkatan tingkatan risiko disaat meningkatnya proporsi peminjaman dan tidak diikuti penambahan total dana pihak ketiga nya (Martínez-Malvar \& Baselga-Pascual, 2020). Begitu juga dengan penelitian (Chiaramonte et al., 2015) bahwa Bank yang meberikan portofolio kredit dengan hutang jangka pendeknya dapat terkena masalah pembiayaan, dikarenakan susahnya untuk mengumpulkan dana pihak ketiga yang berjangka panjang juga dan akhirnya menimbulkan deposit drainage sehingga menimbullkan kenaikan risiko pada bank tersebut. Penelitian Dahir et al., (2018) menyatakan juga bahwa kenaikan risiko likuiditas atau semakin ilikuid nya suatu perbankan dapat menaikan tingkat risiko nya dikarenakan aset liquid mereka nilai nya sama dengan kewajiban liquid mereka dan pinjaman jangka pendek lebih besar dari aset liquid nya.

Berdasarkan penjelasan di atas, maka dirumuskan hipotesis sebagai berikut:

\section{H5 : Terdapat pengaruh antara ilikuiditas dengan risiko perbankan}

\section{Metode Penelitian}

Metode pengumpulan data yang digunakan adalah pengumpulan data sekunder. Data diperoleh secara tidak langsung dari sumber yang telah tersedia. Sumber data pengambilan ini diperoleh dari website Burse Efek Indonesia (BEI) (www.idx.co.id), website Badan Pusat Statistik (www.bps.go.id), website Otoritas Jasa Keuangan (www.ojk.go.id) dan World Bank Data (data.worldbank.org). Data penelitian ini terdiri dari semua perusahaan perbankan yang terdaftar di Bursa Efek Indonesia (BEI) selama periode 2009 - 2019 berjumlah 31 perbankan.

Metode penarikan sampel yang dilakukan dalam penelitian ini dengan cara purposive sampling, dari metode tersebut didapatkan sampel penelitian sebanyak 31 perusahaan pada sektor perbankan yang telah memenuhi kriteria. Bank Syariah dan Bank Daerah yang terdaftar di BEI dikeluarkan dari kriteria sampel pada penelitian ini. 
Teknik analisis yang dipakai dalam penelitian ini adalah Sytem Generalized method of moment (system dynamic panel data estimation)

Adapun Identifikasi variabel pada penelitian ini yaitu untuk mengetahui hubungan antara, varibel independen (Capital Adequacy Ratio, Kualitas Aset, Inefisiensi Manajemen, Profitabilitas, Ilikuiditas) dan variabel control (Konsentrasi Perbankan, Domestic Credit to Private Sector, Tingkat Suku Bunga, Inflasi, Current Accounts, Tingkat Pengangguran) terhadap variabel dependen (Risiko Perbankan), yang masing masing pengukurannya sebagai berikut:

Tabel 1

Variabel dan Pengukuran

\begin{tabular}{|c|c|c|c|c|}
\hline $\begin{array}{c}\text { Jenis } \\
\text { Variabel }\end{array}$ & $\begin{array}{c}\text { Nama } \\
\text { Variabel }\end{array}$ & Simbol & $\begin{array}{c}\text { Definisi } \\
\text { Operasional } \\
\text { Variabel }\end{array}$ & Sumber \\
\hline \multirow{4}{*}{$\begin{array}{l}\text { Variabel } \\
\text { Dependen }\end{array}$} & \multirow{4}{*}{$\begin{array}{l}\text { Risiko } \\
\text { Perbankan }\end{array}$} & & ROA $i, t+E T A i, t$ & \multirow{4}{*}{$\begin{array}{c}\text { (Martínez-Malvar } \\
\& \\
\text { Baselga-Pascual, } \\
2020)\end{array}$} \\
\hline & & Z-Score & $\begin{array}{c}\sigma(R O A) i, t \\
\text { ROA = Net Income }\end{array}$ & \\
\hline & & & $\begin{array}{c}\text { dibagi dengan total } \\
\text { aset }\end{array}$ & \\
\hline & & & $\begin{array}{c}\text { ETA = Modal dibagi } \\
\text { dengan total aset }\end{array}$ & \\
\hline Variabel & Capital & CAR & Modal Bank & (Pinasti \& \\
\hline Independen & $\begin{array}{l}\text { Adequacy } \\
\text { Ratio }\end{array}$ & & $\begin{array}{l}\text { Aset Tertimbang } \\
\text { Menurut Risiko }\end{array}$ & $\begin{array}{l}\text { Mustikawati, } \\
\text { 2018) }\end{array}$ \\
\hline \multirow{8}{*}{$\begin{array}{c}\text { Variabel } \\
\text { Independen }\end{array}$} & Kualitas Aset & LTA & Total Kredit & (Baselga-Pascual \\
\hline & & & Total Aset & et al., 2015) \\
\hline & Inefisiensi & COSTI & Gross Profit & \multirow{6}{*}{$\begin{array}{c}\text { (Martínez-Malvar } \\
\& \\
\text { Baselga-Pascual, } \\
\text { 2020) }\end{array}$} \\
\hline & & & $\overline{\text { Beban Operasional }}$ & \\
\hline & Profitabilitas & ROE & Net Income & \\
\hline & & & $\overline{\text { Total Equity }}$ & \\
\hline & Ilikuiditas & LIQ & Total Kredit & \\
\hline & & & $\begin{array}{c}\text { Total Customer } \\
\text { Deposits }\end{array}$ & \\
\hline \multirow{4}{*}{$\begin{array}{l}\text { Variabel } \\
\text { Kontrol }\end{array}$} & $\begin{array}{c}\text { Konsentrasi } \\
\text { Perbankan }\end{array}$ & $\mathrm{HHI}$ & $10.000 \sum\left[\frac{A_{i t}}{T A_{\mathrm{t}}}\right]^{2}$ & $\begin{array}{c}\text { (Apriadi et al., } \\
\text { 2016) }\end{array}$ \\
\hline & $\begin{array}{c}\text { Kredit } \\
\text { Domestik ke } \\
\text { Pihak Swasta }\end{array}$ & DCPS & $\begin{array}{c}\text { Jumlah sumber daya } \\
\text { keuangan yang } \\
\text { diberikan kepada } \\
\text { sektor swasta oleh } \\
\text { perbankan }\end{array}$ & \multirow{3}{*}{$\begin{array}{c}\text { (Martínez-Malvar } \\
\& \\
\text { Baselga-Pascual, } \\
\text { 2020) }\end{array}$} \\
\hline & $\begin{array}{c}\text { Tingkat Suku } \\
\text { Bunga }\end{array}$ & INT & $\begin{array}{l}\text { Tingkat suku bunga } \\
\text { yang diberikan } \\
\text { perbankan yang } \\
\text { ditetapkan oleh } \\
\text { regulator }\end{array}$ & \\
\hline & Inflasi & INFL & $\begin{array}{c}\text { Rate dari perubahan } \\
\text { harga dalam }\end{array}$ & \\
\hline
\end{tabular}




\begin{tabular}{ccc}
\hline Current & CURRACC & $\begin{array}{c}\text { keseluruhan } \\
\text { ekonomi }\end{array}$ \\
\cline { 2 - 3 } Accounts & $\begin{array}{c}\text { Presentase jumlah } \\
\text { ekspor bersih barang } \\
\text { dan jasa }\end{array}$ \\
\hline Tingkat & UNPL & $\begin{array}{c}\text { Presentase } \\
\text { pengangguran yang } \\
\text { belum bekerja }\end{array}$ \\
\hline
\end{tabular}

Metode pengujian model pada penelitian ini yaitu menggunakan data panel dinamis. Ada 2 pendekatan yang digunakan dalam mengestimasi model regresi data panel dinamis adalah Arellano Bond generalized method of moment (AB GMM) dan system generalized method of moment (SYS GMM). Pengujian yang dilakukan adalah Arellano-Bond test (AB-Test). Uji ini dilakukan untuk mengetahui adanya korelasi antara satu komponen residual dengan komponen residual yang lain pada model $A B$ GMM dan SYS GMM. Pengambilan keputusan pada test ini adalah :

$\mathrm{H}_{0}$ : Tidak terdapat autokorelasi pada sisaan order ke $i$

$\mathrm{H}_{1}$ : Terdapat autokorelasi pada sisaan order ke $i$

Apabila probabilitas $<\alpha$ maka terima $\mathrm{H}_{0}$. Konsistensi $G M M$ order 1 ditujukan dengan nilai statistik uji Arellano-Bond yang signifikan, sedangkan konsistensi GMM pada order 2 ditujukan dengan nilai statistik uji Arellano-Bond yang tidak signifikan (Dessy \& Setiawan, 2016). Berikut adalah pengujiannya :

\section{Tabel 2}

\section{Hasil Uji Model}

\begin{tabular}{|c|c|c|c|c|}
\hline Model & Order & Probabilitas & Keputusan & Keterangan \\
\hline \multirow[b]{2}{*}{$\mathrm{AB}-G M M$} & 1 & 0.4981 & $\mathrm{H}_{0}$ ditolak & \multirow{2}{*}{$\begin{array}{c}\text { Model tidak } \\
\text { dapat } \\
\text { digunakan }\end{array}$} \\
\hline & 2 & 0.4151 & $\mathrm{H}_{0}$ diterima & \\
\hline \multirow[t]{2}{*}{ SYS-GMM } & 1 & 0.0622 & $\mathrm{H}_{0}$ diterima & \multirow{2}{*}{$\begin{array}{c}\text { Model dapa } \\
\text { digunakan }\end{array}$} \\
\hline & 2 & 0.6882 & $\mathrm{H}_{0}$ diterima & \\
\hline
\end{tabular}

Berdasarkan tabel hasil uji $\mathrm{AB}-G M M$ di atas hasil menunjukan bahwa nilai probabilitas order 1 sebesar sebesar $0.4981>0.10$ dan order 2 sebesar $0.4151>0.10$, maka keputusan yang diperoleh yaitu $\mathrm{H}_{0}$ ditolak sehingga model $\mathrm{AB}-G M M$ tidak konsisten dan model ini tidak dapat dipergunakan.

Berdasarkan tabel hasil uji SYS - GMM di atas hasil menunjukan bahwa nilai probabilitas order 1 sebesar $0.0622<0.10$ dan order 2 sebesar $0.6882>0.10$, maka keputusan yang diperoleh yaitu $\mathrm{H}_{0}$ diterima sehingga model $S Y S-G M M$ konsisten dan model ini dapat dipergunakan. 


\section{Hasil dan Pembahasan}

\section{A. Hasil Penelitian}

1. Analisis Uji Statistik Deskriptif

Tabel 3

Hasil Statistika

\begin{tabular}{ccccc}
\hline & Mean & Maximum & Minimum & Std. Dev \\
\hline ZSCORE & 65.4209 & 4434.6280 & 1.6670 & 243.2989 \\
\hline ZSCORE $_{\mathrm{t}-1}$ & 66.6614 & 4434.6280 & 1.6670 & 255.0047 \\
\hline CAR & 29.0247 & 2529.4200 & 9.4100 & 138.5517 \\
\hline LTA & 62.6215 & 80.8700 & 1.3600 & 10.3763 \\
\hline COSTI & 76.5666 & 1497.0600 & -83.2400 & 97.7816 \\
\hline ROA & 7.5418 & 46.6500 & -82.6200 & 12.5004 \\
\hline LIQ & 83.5129 & 171.3196 & 34.5710 & 16.2814 \\
\hline HHI & 36.8383 & 447.3100 & 0 & 92.0102 \\
\hline DCPS & 34.9746 & 39.4024 & 27.2530 & 4.4380 \\
\hline INT & 6.2438 & 9.2244 & -1.7461 & 2.8404 \\
\hline INFL & 5.5731 & 15.2643 & 1.6045 & 3.5896 \\
\hline CURRACC & -1.5637 & 1.9698 & -3.1900 & 1.6613 \\
\hline UNPL & 4.5860 & 6.1060 & 3.6210 & 0.7146 \\
\hline
\end{tabular}

Sumber : Data Output Stata 13.0

Berdasarkan hasil uji statistik deskriptif pada tabel 3, terdapat interpretasi yang dapat dijelaskan sebagai berikut :

Risiko perbankan (ZSCORE) memiliki nilai rata-rata sebesar 65.4209 dan standar deviasi sebesar 243.2989. Adapun nilai maksimum dari zscore sebesar 4434.6280 dan nilai minimum dari Zscore sebesar 1.6670. Kemudian untuk lagged Zscore memiliki nilai rata-rata sebesar 66.66136 dan standar deviasi sebesar 255.0047 .

Capital Adequacy Ratio (CAR) memiliki nilai rata-rata sebesar 29.0247 dan standar deviasi sebesar 138.5517. Adapun nilai maksimum dari CAR sebesar 2529.4200 dan nilai minimum dari CAR sebesar 9.4100.

Kualitas aset (LTA) memiliki nilai rata-rata sebesar 62.6215 dan standar deviasi sebesar 10.3763. Adapun nilai maksimum dari LTA sebesar 80.8700 dan nilai minimum dari LTA sebesar 1.3600.

Inefisiensi manajemen (COSTI) memiliki nilai rata-rata sebesar 76.5666 dan standar deviasi sebesar 97.7816. Adapun nilai maksimum dari COSTI sebesar 1497.0600 dan nilai minimum dari COST sebesar -83.2400.

Profitabilitas (ROE) memiliki nilai rata-rata sebesar 7.5418 dan standar deviasi sebesar 12.5004. Adapun nilai maksimum dari ROE sebesar 46.6500 dan nilai minimum dari ROE sebesar -82.6200 . 
Ilikuiditas (LIQ) memiliki nilai rata-rata sebesar 83.5129 dan standar deviasi sebesar 16.2814. Adapun nilai maksimum dari LIQ sebesar 171.3196 dan nilai minimum dari LIQ sebesar 34.5710.

\section{Uji Analisa Data}

1) Uji Signifikansi (Uji z)

Tabel 4

Hasil Uji Z

\begin{tabular}{|c|c|c|c|c|}
\hline \multirow{3}{*}{ Model } & \multirow{3}{*}{$\begin{array}{c}\text { Variabel } \\
\text { Independen }\end{array}$} & \multicolumn{3}{|c|}{ Variabel Dependen } \\
\hline & & \multicolumn{3}{|c|}{ Z-SCORE } \\
\hline & & Koefisien & $\mathbf{P}>|\mathbf{z}|$ & Kesimpulan \\
\hline \multirow{8}{*}{$\begin{array}{c}\text { SYS } \\
\text { GMM }\end{array}$} & Konstanta & 7.4454 & - & - \\
\hline & ZSCORE t $_{-1}$ & -0.0064 & 0.000 & $\begin{array}{c}\text { Negatif } \\
\text { Signifikan }\end{array}$ \\
\hline & CAR & 1.8537 & 0.000 & $\begin{array}{c}\text { Positif } \\
\text { Signifikan }\end{array}$ \\
\hline & LTA & 0.0157 & 0.647 & $\begin{array}{c}\text { Tidak } \\
\text { Signifikan }\end{array}$ \\
\hline & COSTI & -0.0102 & 0.005 & $\begin{array}{c}\text { Negatif } \\
\text { Signifikan }\end{array}$ \\
\hline & ROE & 0.1307 & 0.000 & $\begin{array}{c}\text { Positif } \\
\text { Signifikan }\end{array}$ \\
\hline & LIQ & -0.1430 & 0.000 & $\begin{array}{c}\text { Negatif } \\
\text { Signifikan }\end{array}$ \\
\hline & HHI & 0.1841 & 0.003 & $\begin{array}{c}\text { Positif } \\
\text { Signifikan }\end{array}$ \\
\hline \multirow[t]{5}{*}{ SYS GMM } & DCPS & 1.2128 & 0.000 & $\begin{array}{c}\text { Positif } \\
\text { Signifikan }\end{array}$ \\
\hline & INT & -1.6904 & 0.000 & $\begin{array}{c}\text { Negatif } \\
\text { Signifikan }\end{array}$ \\
\hline & INFL & -1.6904 & 0.000 & $\begin{array}{c}\text { Negatif } \\
\text { Signifikan }\end{array}$ \\
\hline & CURRACC & 1.5521 & 0.000 & $\begin{array}{c}\text { Positif } \\
\text { Signifikan }\end{array}$ \\
\hline & UNPL & -3.9629 & 0.000 & $\begin{array}{c}\text { Negatif } \\
\text { Signifikan }\end{array}$ \\
\hline
\end{tabular}

2) Uji Robust

Sumber : Data Output Stata 13.0

Untuk menguji ketahanan dan ketidak konsistenan model SYS GMM maka digunakan tes dengan menerapkan regresi Ordinary Least Square (OLS) (Martínez-Malvar \& Baselga-Pascual, 2020). Kriteria pengambilan hasil uji ini adalah nilai koefisien lag variabel $\mathrm{Y}_{\mathrm{t}-1}<1$ (Dessy \& Setiawan, 2016). 
Tabel 5

Hasil Uji Robust

\begin{tabular}{|c|c|c|c|c|}
\hline \multirow[t]{3}{*}{ Model } & \multirow{3}{*}{$\begin{array}{c}\text { Variabel } \\
\text { Independen }\end{array}$} & \multicolumn{3}{|c|}{ Variabel Dependen } \\
\hline & & \multicolumn{3}{|c|}{ ZSCORE } \\
\hline & & Koefisien & $\mathbf{P}>|\mathbf{t}|$ & Kesimpulan \\
\hline \multirow{13}{*}{$O L S$} & Konstanta & 19.0612 & - & - \\
\hline & $\mathrm{ZSCORE} \mathrm{t}_{-1}$ & 0.1361 & 0.000 & $\begin{array}{c}\text { Positif } \\
\text { Signifikan }\end{array}$ \\
\hline & CAR & 0.5635 & 0.003 & $\begin{array}{c}\text { Positif } \\
\text { Signifikan }\end{array}$ \\
\hline & LTA & -0.0005 & 0.998 & $\begin{array}{c}\text { Tidak } \\
\text { Signifikan }\end{array}$ \\
\hline & COSTI & -0.0190 & 0.358 & $\begin{array}{c}\text { Tidak } \\
\text { Signifikan }\end{array}$ \\
\hline & ROE & 0.4496 & 0.015 & $\begin{array}{c}\text { Positif } \\
\text { Signifikan }\end{array}$ \\
\hline & LIQ & -0.2445 & 0.081 & $\begin{array}{c}\text { Negatif } \\
\text { Signifikan }\end{array}$ \\
\hline & HHI & 0.0275 & 0.076 & $\begin{array}{c}\text { Positif } \\
\text { Signifikan }\end{array}$ \\
\hline & DCPS & 1.7260 & 0.0013 & $\begin{array}{c}\text { Positif } \\
\text { Signifikan }\end{array}$ \\
\hline & INT & -2.8786 & 0.217 & $\begin{array}{c}\text { Tidak } \\
\text { Signifikan }\end{array}$ \\
\hline & INFL & -1.9256 & 0.366 & $\begin{array}{c}\text { Tidak } \\
\text { Signifikan }\end{array}$ \\
\hline & CURRACC & 0.6520 & 0.706 & $\begin{array}{c}\text { Tidak } \\
\text { Signifikan }\end{array}$ \\
\hline & UNPL & -0.4260 & 0.936 & $\begin{array}{c}\text { Tidak } \\
\text { Signifikan }\end{array}$ \\
\hline
\end{tabular}

Sumber: Data Output Stata 13.0

Nilai koefisien lag zscore OLS sebesar 0.1361 dan nilai lag zscore SYS GMM sebesar -0.0064 . Nilai koefisien $-0.0064<0.1361$ dan $0.1361<1$. Hasil uji memperlihatkan bahwa model SYS GMM tidak bias dan konsisten.

3) Analisis Regresi Panel Dinamis

Analisis regresi panel dinamis memiliki tujuan untuk melihat pengaruh antara variabel dependen dan variabel independen pada perusahaan sektor perbankan. Berikut merupakan hasil persamaan regresi dari penelitian ini:

ZSCORE $=7.4554-0.0064$ ZSCORE $_{\mathrm{t}-1}+1.8537 \mathrm{CAR}+0.0157 \mathrm{LTA}$

$$
\begin{aligned}
& -0.0102 \mathrm{COSTI}+0.1307 \mathrm{ROE}-0.1430 \mathrm{LIQR}+0.1841 \mathrm{HHI} \\
& +1.2128 \mathrm{DCPS}-1.6904 \mathrm{INT}-0.6891 \mathrm{INFL}+1.5521 \mathrm{CURRACC} \\
& -3.9629 \mathrm{UNPL}
\end{aligned}
$$




\section{B. Pembahasan}

\section{H1: Terdapat pengaruh antara $C A R$ dan Risiko Perbankan}

Berdasarkan hasil penelitian pengujian statistik didapatkan nilai signifikansi sebesar $0.000<0.10$ dan koefisien sebesar 1.8537 yang menyimpulkan adanya pengaruh positif dan signifikan antara CAR dan ZSCORE. Nilai ZSCORE ini berbanding negatif dengan Risiko Perbankan, yang berati $C A R$ berpengaruh negatif terhadap risiko perbankan. Hasil ini sesuai dengan penelitian Baselga-Pascual et al., (2015) bahwa ada hubungan negatif antara $C A R$ dan Risiko perbankan, dan sejalan juga dengan penelitian Laeven et al., (2016) bahwa tingkat modal yang tinggi membuat bank lebih menyaring nasabahnya secara instensif dan tingkat kecukupan permodalan yang tinggi membuat bank lebih stabil dan tangguh dalam menjalankan operasional nya, dan apabila perbankan mengalami goncangan, bank masih memiliki modal yang cukup untuk menyerap risiko - risiko nya. Hasil yang berbeda ditemukan dalam penelitian Nguyen et al., (2019), yang menyatakan terdapat hasil positif antara $C A R$ dengan risiko perbankan dikarenakan besarnya rasio permodalan dapat mendorong perbankan untuk menaikan risikonya.

2. H2: Tedapat pengaruh antara Kualitas Aset (LTA) dan Risiko Perbankan

Dari hasil penelitian pengujian statistik didapatkan nilai signifikansi sebesar 0.647 yang artinya lebih besar dari tingkat signifikansi 0.10 yang menunjukkan tidak ada pengaruh signifikan. Besar koefisien sebesar 0.0157118 . Hasil penelitian ini menyimpulkan tidak adanya pengaruh signifikan antara Kualitas Aset dan ZSCORE, atau Kualitas Aset tidak berpengaruh terhadap Risiko Perbankan. Hasil penelitian ini tidak mendukung penelitian Martínez-Malvar \& Baselga-Pascual (2020), Baudino, Orlandi, \& Zamil, (2018) dan Liem, Son, \& Nghia, (2016), namun hasil ini sesuai dengan penelitian dari Baselga-Pascual et al., (2015) di mana hasil yang tidak berpengaruh secara signifikan ini dikarenakan Kualitas aset ini tidak sepenuhnya tercermin dalam proporsi pinjaman atas aset dan pada perbankan di Indonesia sudah lebih memperhatikan dan memitigasi risiko nya apabila terjadi kenaikan atau penurunan pada kualitas aset nya, sehingga hal ini tidak mempengaruhi risiko dari perbankan itu sendiri.

\section{H3: Terdapat pengaruh antara Inefisiensi (COSTI) dan Risiko Perbankan}

Berdasarkan hasil penelitian pengujian statistik didapatkan nilai signifikansi sebesar 0.005 dan lebih kecil tingkat signifikansi 0.10 yang menunjukkan pengaruh signifikan dan koefisien sebesar -0.01024. Dapat disimpulkan adanya pengaruh positif antara Inefisensi dan Risiko Perbankan. Hasil ini sejalan dengn penelitian Huljak, Martin, \& Moccero (2019) dan Louzis, Vouldis, \& Metaxas (2012) bahwa Bank yang lebih efisien cenderung memiliki biaya rata-rata yang lebih rendah dan biaya pendapatan yang lebih rendah sehingga dapat mengurangi risiko perbankan. Selain itu semakin rendahnya efisiensi dalam suatu perbankan dapat meningkatkan risiko NPL sebagai salah 
satu contohnya, dikarenakan kurangnya ketrampilan dalam penilaian kredit, penilaian agunan dan pematauan pinjaman. Namun hasil ini berbeda dengan penelitian Martínez-Malvar \& Baselga-Pascual (2020) yang menyatakan tidak ada pengaruh antara keduanya dikarenakan terdapat nya perbedaan struktur biaya antar perbankan, sehingga tidak memperngaruhi dari risiko perbankan itu sendiri.

\section{H4: Terdapat pengaruh antara Profitabilitas (ROE) dan Risiko Perbankan}

Hasil yang didapat dari pengujian statistik didapatkan nilai signifikansi sebesar $0.000<0.10$ dan menunjukkan pengaruh signifikan dan nilai koefisien 0.1307 , ini menunjukan pengaruh positif dan signifikan antara profitabilitas dan ZSCORE atau pengaruh negatif terhadap Risiko perbankan. Hasil ini berbeda dengan penemuan Martínez-Malvar \& Baselga-Pascual (2020) yang menyatakan tidak ada keberpengaruhan antara profitabilitas dan risiko perbankan. Namun hasil yang sama dihasilkan oleh Baselga-Pascual et al. (2015) bahwa perbankan yang lebih menguntungkan dalam operasional nya cenderung lebih stabil dan menurunkan tingkat risikonya. Hasil ini diperkuat juga oleh Poghosyan \& Čihak (2011), yang menemukan bahwa perbankan yang memiliki tingkat profitabilitas tinggi dapat mengatasi segala risiko-risiko yang terjadi selama operasional nya. Köhler (2015) menemukan juga hasil yang sama, bahwa perbankan yang memiliki pendapatan nya lebih tinggi dapat mengurangi dan mengantisipasi risiko-risiko yang akan datang.

\section{H5: Terdapat pengaruh antara Ilikuiditas (LIQ) dan Risiko Perbankan}

Ilikuiditas dan risiko perbankan dinyatakan dalam uji statistik bahwa berkorelasi positif dengan risiko perbankan atau berkorelasi negatif dengan ZSCORE. Nilai signifikansi sebesar 0.000 dan kurang dari tingkat signifikansi 0.10 dengan besaran koefisien sebesar -0.1430. Hasil penelitian ini sejalan dengan hasil (Martínez-Malvar \& Baselga-Pascual, 2020), bahwa bank yang kurang likuid atau ilikuid adalah kondisi di mana meningkatnya proporsi pinjaman yang tidak diikuti oleh penambahan total dana pihak ketiga nya, kondisi seperti ini yang akan menaikan risiko likuiditas dari suatu perbankan. Serupa dengan penelitian Chiaramonte et al., (2015) dan Dahir et al., (2018) bahwa bank yang meberikan portofolio kredit dapat terkena masalah pembiayaan, dikarenakan susahnya untuk mengumpulkan dana pihak ketiga yang berjangka panjang juga dan akhirnya menimbulkan deposit drainage sehingga menimbullkan kenaikan risiko pada bank tersebut dan juga dikarenakan aset liquid mereka nilai nya sama dengan kewajiban liquid mereka.

Pada variabel kontrol, Konsentrasi Perbankan (HHI) dengan nilai signifikansi sebesar 0.003 yang lebih kecil dari 0.10 dan koefisien sebsar 0.1841 yang artinya Konsentrasi Perbankan berpengaruh positif terhadap ZSCORE atau berpengaruh negatif terhadap risiko perbankan. Penelitian ini menolak hasil dari Martínez-Malvar \& Baselga-Pascual (2020) namun sejalan dengan penelitian Apriadi et al., (2016) bahwa peningkatan konsentrasi (ditandai dengan turunnya 
HHI) akan menaikan risiko perbankan, dikarenakan menaikan market power dan menurunkan margin keuntungan. Dalam situasi ini perbankan akan lebih mengambil risiko untuk meningkatkan keuntungan nya dan menurunkan stabilitasnya.

Kredit domestic kepada pihak swasta (DCPS) menghasilkan nilai signifikansi sebesar $0.000<0.10$ dan koefisien sebesar 1.2129 yang mensyaratkan bahwa DCPS berpengaruh positif terhadap ZSCORE atau berpengaruh positif terhadap risiko perbankan. Hasil ini berbeda dengan penelitian Martínez-Malvar \& Baselga-Pascual (2020). Ini dikarenakan disaat DCPS meningkat maka nasabah-nasabah kredit akan mempunyai akses terhadap berbagai financial resources dan tentu akan menurunkan risiko perbankan tersebut.

Tingkat suku bunga (INT) memiliki koefisien sebesar -1.6904 dengan nilai signifikansi sebesar 0.000 . Nilai signifikansi ini lebih kecil dari 0.10 yang artinya INT berpengaruh negatif terhadap ZSCORE atau berpengarugh positif terhadap risiko perbankan. Hal ini tidak sejalan dengan penelitian Martínez-Malvar \& Baselga-Pascual (2020), dikarenakan di Indonesia yang diwakilkan oleh sampel bank dalam penelitian ini apabila tingkat suku bunga meningkat, maka kecenderungan gagal pembayaran bunga akan meningkat, dan akan menaikan risiko dari setiap perbankan.

Inflasi (INFL) dengan nilai signifikansi sebesar 0.000 dan koefisien sebesar -0.6891 yang artinya inflasi berpengaruh negative terhadap ZSCORE atau berpengaruh positif terhadap risiko perbankan dikarenakan hasil nilai signifikansi < 0.10. Hasil ini sejalan dengan penelitian Davis et al., (2011) di mana kebiasaan dalam perbankan dalam negara berkembang, inflasi dapat melipatgandakan kemungkinan krisis perbankan sistemik dan juga di saat inflasi naik perbankan harus juga menaikan suku bunga dana pihak ketiga nya namun bertolak belakang dengan penelitian Martínez-Malvar \& Baselga-Pascual (2020) yang menyebutkan tidak adanya hubungan antara Inflasi dan Risiko Perbankan.

Current Account (CURRACC) memiliki nilai signifikansi sebesar 0.000 dan koefisien sebesar 1.5521. Nilai signifikansi lebih kecil dari 0.10 yang artinya CURRACC berpengaruh positif terhadap ZSCORE atau berpengaruh negatif terhadap risiko perbankan. Hal ini sejalan dengan penelitian (Kauko, 2012) di mana pertumbuhan kredit yang dikombinasikan dengan defisit pada Current Account nya dapat berkontribusi pada kerentanan sistem perbankan. Martínez-Malvar \& Baselga-Pascual (2020) mengkonfirmasi bahwa tidak ada pengaruh antara Current Account dengan Risiko Perbankan.

Nilai signifikansi dari Tingkat pengangguran (UNPL) sebesar 0.000 dan lebih keci dari tingkat singnifikani 0.10dan memiliki koefisien sebesar -3.9629 yang artinya tingkat pengangguran berpengaruh negative terhadap ZSCORE atau berpengaruh positif terhadap risiko perbankan. Hasil ini berbeda dengan penelitian Khan et al., (2017) dan Martínez-Malvar \& Baselga-Pascual (2020) 
dikarenakan di Indonesia, dengan memperhatikan sistem makro-politiknya di mana di saat tingginya angka kenaikan pengangguran akan mempengaruhi kondisi, seperti penjarahan, kerusuhan atau kejahatan dikarenakan banyak masyarakat yang terkena imbas dari pengangguran. Kondisi ini akan membuat masyarakat yang tidak terkena atau belum terkena imbas nya akan melakukan Rush Money dari perbankan. Keadaan rush money seperti itu lah yang akan menaikan risiko dari perbankan dan juga akan menggangu sistem ekonomi nasional, di mana nantinya akan mengganggu pengembalian pinjaman kredit kepada perbankan.

\section{Kesimpulan}

Hasil penelitian menunjukan adanya pengaruh baik dari variabel mikro dan variabel makro nya. Pada variabel mikro Seperti CAR dan profitabilitas berpengaruh negatif terhadap risiko perbankan, ini dapat dijadikan acuan untuk pemangku jabatan untuk menguatkan 2 variabel mikro tersebut. Di saat rasio kecukupan modal dan keuntungan perbankan meningkat tentu bank tersebut akan kuat dalam menghadapi goncangan keuangan yang sudah terjadi dan akan terjadi dalam operasionalnya, dikarenakan Bank mempunyai cukup persediaan finansialnya untuk menopang kondisi tersebut. Selain itu para manajer perbankan harus selalu menaikan 2 unsur tersebut agar rasio permodalan dan profitabilitas selalu meningkat. Selain itu ada 2 variabel mikro lagi yang berpengaruh negatif terhadap risiko perbankan, yaitu Inefisiensi dan Ilikuiditas. Di mana 2 kondisi ini harus ditekan oleh para manajer perbankan, untuk Inefisensi, para manajer harus selalu menekan beban bunga agar dapat menghasilkan pendapatan bunga bersih yang lebih besar. Dari sisi operation expense pun manajer harus selalu menekan beban operational nya, agar didapatkan rasio Cost to Income yang efisien dan juga pendapatan bunga bersih masih dapat menanggung beban-beban operasionalnya. Tingkat likuiditas pun tidak boleh luput dari perhatian para manajer perbankan, di mana bila risiko likuiditas ini naik dan perbankan menjadi dalam suatu kondisi ilikuid yang dapat menaikan risiko nya. Manajer harus selalu memperhatikan tingkat pinjaman kredit yang diberikan kepada nasabah, dikarenakan harus selalu diikuti juga dengan kenaikan tingkat dana pihak ketiga dan memantau pemberian kredit jangka panjang nya, apakah masih bisa ditopang dengan penghimpunan dana pihak ketiga nya yang relatif bersifat pendek.

Begitu juga pada variabel makro nya, Konsentrasi Perbankan, Kredit Domestik terhadap Pihak Swasta dan Current Accounts berpengaruh positif terhadap risiko perbankan. Konsentrasi perbankan yang meningkat dapat menaikan risiko perbankan, sehingga untuk menurunkan risikonya, konsentrasi perbankan ini hendaknya diturunkan, untuk dapat menghasilkan perbankan yang efisien dan stabil. Dapat dilakukan dengan cara penggabungan bank-bank yang memiliki karakterisitik yang sama, misalkan penggabungan bank-bank BUMN atau bank swasta lain, sehingga hasil penggabungan ini akan menciptakan bank yang mampu bersaing di tingkat regional maupun internasional, sehingga tingkat konsentrasi nya tidak meningkat dan menambah 
risiko dari perbankan itu sendiri. Keadaan dimana Kredit Domestik terhadap Sektor Swasta yang meningkat dapat menurunkan risiko perbankan, bagi perbankan harus selalu mendorong kredit terhadap masyarakat atau perusahaan yang sesuai dengan kriteria agar sistem ekonomi pun terus berputar dan bermunculan usaha-usaha baru atau terekspansinya suatu bisnis. Current Accounts yang meningkat juga mengindikasikan surplus pada sisi ekspor. Manager harus melihat bahwa ini menandakan kondisi yang sangat baik, dan bisa mendorong sektor usaha untuk menaikan perdagangan ke luar negeri dan juga dapat meningkatkan likuiditas valas bagi perbankan dan tentunya bagi dalam negeri sendiri.

Tingkat Suku Bunga, dan Inflasi berhubungan positif dengan risiko perbankan. Para manajer harus benar-benar memperhatikan nilai inflasi. Perbankan harus membuat kebijakan bunga bank yang tidak terlalu mebebani nasabah kredit, agar kenaikan tingkat suku bunga kredit yang dapat juga diakibatkan oleh inflasi tidak memberatkan tingkat suku bunga pembiayaan dan masih dapat dijangkau oleh para nasabah. Dikarenakan apabila kondisi inflasi terjadi, akan terjadinya juga kenaikan biaya - biaya produksi yang dapat menganggu arus kas para nasabah, yang dihawatirkan dapat meningkatkan risiko gagal bayar kreditnya.

Begitu juga dengan Tingkat Pengangguran yang berhubungan positif dengan risiko perbankan, di mana para manajer perbankan harus sudah dapat mengantisipasi dengan memitigasi atau menganalisis mana saja sektor usaha yang memang tidak terlalu berimbas dengan maraknya pemutusan hubungan kerja, sehingga manajer pun dapat mengalokasikan kredit secara optimal pada sektor tersebut untuk mencegah risiko risiko yang akan mempengaruhi perbankan.

Bagi investor sebelum menanamkan modal nya terutama harus memperhatikan nilai dari Rasio Kecukupan Modal. Karena kenaikan pada komponen ini menandakan bahwa bank mempunyai komponen modal yang baik sehingga selalu dapat menjalankan fungsi utamanya dan dapat menyerap risiko-risiko akibat aktivitas operasionalnya. Variabel lainnya seperti Inefisiensi, Likuiditas, Profitabilitas pun harus diperhatikan dengan seksama untuk menghindari risiko-risiko kerugian karena akan berpengaruh terhadap Return yang akan diterima oleh investor. Investor juga harus mempertimbangkan sektor makro ekonomi di Indonesia dalam membuat keputusan investasi, seperti di sektor inflasi dan tingkat suku bunga yang tinggi dapat menaikan risiko perbankan sehingga investor dapat membagi penanaman modalnya tidak hanya di satu perbankan. Begitu juga faktor lainnya seperti Kredit Domestik ke sektor swasta atau Current Account yang menandakan bahwa sektor usaha di Indonesia sedang berkembang sehingga investor tetap harus membagi penanaman modal nya agar lebih optimal walaupun akan berinvestasi lebih besar.

Dalam penelitian ini hanya digunakan sektor perbankan yang terdaftar pada sektor perbankan yang terdaftar pada Bursa Efek Indonesia. Selain itu variabel Risiko Perbankan hanya diukur menggunakan Z-Score dan Variabel Makro hanya terbatas pada Konsentrasi Perbankan, Inflasi, Tingkat Suku Bunga, Current Accounts, Kredit Domestik ke sektor swasta, Tingkat Pengangguran. Untuk sampel penelitian dapat 
ditambah menjadi lebih besar seperti contoh Asia Tenggara atau Asia, seperti yang diteliti oleh Maudos (2017) melibatkan perbankan di Eropa. Untuk risiko perbankan dapat diukur juga menggunakan Non Performing Loan. Variabel makro lainnya yang dapat diteliti adalah Capital Stringency Index, Supervisory Power Index, Private Monitoring Index, dan Activity Restrictions Index (Baselga-Pascual et al., 2015) atau Bank Sector Development dan Stock Market Development (Liem et al., 2016) yang diharapkan dapat menambah refrensi penelitian berikutnya

\section{BIBLIOGRAFI}

Agoraki, M. E. K., Delis, M. D., \& Pasiouras, F. (2011). Regulations, competition and bank risk-taking in transition countries. Journal of Financial Stability, 7(1), 38-48.

Apriadi, I., Sembel, R., Santosa, P. W., \& Firdaus, M. (2016). Banking fragility in Indonesia: A panel vector autoregression approach. International Journal of Applied Business and Economic Research, 14(14), 1193-1224.

Baselga-Pascual, L., Trujillo-Ponce, A., \& Cardone-Riportella, C. (2015). Factors influencing bank risk in Europe: Evidence from the financial crisis. North American Journal of Economics and Finance, 34, 138-166.

Baudino, P., Orlandi, J., \& Zamil, R. (2018). The identification and measurement of non-performing assets: A cross-country comparison. In FSI Insights on Policy Implementation. Retrieved from www.bis.org/emailalerts.htm.

Chiaramonte, L., Croci, E., \& Poli, F. (2015). Should we trust the Z-score? Evidence from the European Banking Industry. Global Finance Journal, 28, 111-131.

Dahir, A. M., Mahat, F. B., \& Ali, N. A. Bin. (2018). Funding liquidity risk and bank risk-taking in BRICS countries: An application of system GMM approach. International Journal of Emerging Markets, 13(1), 231-248.

Davis, E. P., Karim, D., \& Liadze, I. (2011). Should multivariate early warning systems for banking crises pool across regions? Review of World Economics, 147(4), 693716.

Demirguc-Kunt, A., Detragiache, E., \& Merrouche, O. (2013). Bank capital: Lessons from the financial crisis. Journal of Money, Credit and Banking, 45(6), 11471164.

Dessy, N., \& Setiawan. (2016). Pemodelan Pertumbuhan Ekonomi Indonesia Menggunakan Data Panel Dinamis dengan Pendekatan Generalized Method of Moment Arellano-Bond. Jurnal Sains Dan Seni Its, 5(2), 205-210. Retrieved from https://media.neliti.com/media/publications/132303-ID-pemodelan-pertumbuhanekonomi-indonesia.pdf

Duca, M. Lo, \& Peltonen, T. A. (2013). Assessing systemic risks and predicting 
systemic events. Journal of Banking and Finance, 37(7), 2183-2195.

Edirisuriya, P., Gunasekarage, A., \& Perera, S. (2019). Product diversification and bank risk: evidence from South Asian banking institutions. Applied Economics, 51(5), 444-464.

El-Chaarani, H. (2019). Determinants of bank liquidity in the Middle East region. International Review of Management and Marketing, 9(2), 64.

Huljak, I., Martin, R., \& Moccero, D. (2019). The cost-efficiency and productivity growth of euro area banks. August ECB Working Paper, (2305).

Kauko, K. (2012). External deficits and non-performing loans in the recent financial crisis. Economics Letters, 115(2), 196-199.

Khan, M. S., Scheule, H., \& Wu, E. (2017). Funding liquidity and bank risk taking. Journal of Banking and Finance, 82, 203-216.

Köhler, M. (2015). Which banks are more risky? The impact of business models on Bank Stability. Journal of Financial Stability, 16, 195-212.

Laeven, L., Ratnovski, L., \& Tong, H. (2016). Bank size, capital, and systemic risk: Some international evidence. Journal of Banking and Finance, 69(June), S25-S34.

Li, X., \& Malone, C. B. (2016). Measuring Bank Risk: An Exploration of Z-Score. SSRN Electronic Journal, 10(January), 1-23.

Liem, N. T., Son, T. H., \& Nghia, H. T. (2016). Factors Affecting Bank Risk-Taking: Evidence from Southeast Asian Countries. Journal of Economics Development, 23(2), 120-136.

Louzis, D. P., Vouldis, A. T., \& Metaxas, V. L. (2012). Macroeconomic and bankspecific determinants of non-performing loans in Greece: A comparative study of mortgage, business and consumer loan portfolios. Journal of Banking and Finance, 36(4), 1012-1027.

Macchiarelli, C. (2018). Post-crisis Excess Liquidity and Bank Lending. Brussels: European Parliament, (September).

Martínez-Malvar, M., \& Baselga-Pascual, L. (2020). Bank risk determinants in Latin America. Risks, 8(3), 1-20.

Maudos, J. (2017). Income structure, profitability and risk in the European banking sector: The impact of the crisis. Research in International Business and Finance, 39, 85-101.

Nguyen, Q. T. T., Nguyen, S. T. B., \& Nguyen, Q. V. (2019). Can Higher Capital Discipline Bank Risk: Evidence from a Meta-Analysis. Journal of Risk and 
Financial Management, 12(3), 134.

Noman, A. H. M., Gee, C. S., \& Isa, C. R. (2018). Does bank regulation matter on the relationship between competition and financial stability? Evidence from Southeast Asian countries. Pacific Basin Finance Journal, 48(December 2017), 144-161.

Obstfeld, M. (2012). Does the current account still matter? American Economic Review, 102(3), 1-23.

Petria, N., Capraru, B., \& Ihnatov, I. (2015). Determinants of Banks' Profitability: Evidence from EU 27 Banking Systems. Procedia Economics and Finance, 20(September), 518-524.

Pinasti, W. F., \& Mustikawati, R. I. (2018). Pengaruh Car, Bopo, Npl, Nim Dan Ldr Terhadap Profitabilitas Bank Umum Periode 2011-2015. Nominal, Barometer Riset Akuntansi Dan Manajemen, 7(1), 1-15.

Poghosyan, T., \& Čihak, M. (2011). Determinants of Bank Distress in Europe: Evidence from a New Data Set. Journal of Financial Services Research, 40(3), $163-184$.

Purba, H. Y., Darminto, \& NP Endang, M. G. W. (2015). Analisis CAMEL Untuk Menilai Performance Perusahaan Perbankan. Jurnal Administrasi Bisnis (JAB), 29(1), 86-94.

Puspadjuita, E. A. R. (2017). Factors that Influence the Rate of Unemployment in Indonesia. International Journal of Economics and Finance, 10(1), 140.

Reinhart, C. M., \& Rogoff, K. S. (2013). Banking crises: An equal opportunity menace. Journal of Banking and Finance, 37(11), 4557-4573.

Salsabila, H. A., \& Iriyadi, I. (2020). Evaluasi Atas Penerapan Sistem Informasi Akademik Dan Keuangan Terhadap Tingkat Kepuasan Mahasiswa. JAS-PT (Jurnal Analisis Sistem Pendidikan Tinggi Indonesia), 4(2), 137.

Simatupang, H. B. (2019). Peranan perbankan dalam meningkatkan perekonomian indonesia. Jurnal Riset Akuntansi Multiparadigma, 6(2), 136-146. Retrieved from https://jurnal.uisu.ac.id/index.php/JRAM/article/view/2184/1510

Tran, N., Ha, T., \& Quyen, G. (2018). International Journal of Economics and Financial Issues The Impact of Funding Liquidity on Risk-taking Behaviour of Vietnamese Banks: Approaching by Z-Score Measure. International Journal of Economics and Financial Issues, 8(3), 29-35. 